\title{
Expendable Graphite as an Efficient Flame-Retardant for Novel Partial Bio-Based Rigid Polyurethane Foams
}

\author{
Felipe M. de Souza ${ }^{1}$, Jonghyun Choi ${ }^{1}$, Sanket Bhoyate ${ }^{2}$, Pawan K. Kahol ${ }^{3}$ \\ and Ram K. Gupta 1,4,*iD \\ 1 Department of Chemistry, Pittsburg State University, Pittsburg, KS 66762, USA; felipe.ms@ufu.br (F.M.d.S.); \\ jonghyunchoi09@gmail.com (J.C.) \\ 2 Department of Materials Science and Engineering, University of North Texas, Denton, TX 76203, USA; \\ sanketbhoyate931@gmail.com \\ 3 Department of Physics, Pittsburg State University, Pittsburg, KS 66762, USA; pkahol@pittstate.edu \\ 4 Kansas Polymer Research Center, Pittsburg State University, Pittsburg, KS 66762, USA \\ * Correspondence: ramguptamsu@gmail.com or rgupta@pittstate.edu; Tel.: +1-620-235-4763; \\ Fax: +1-620-235-4003
}

Received: 9 April 2020; Accepted: 28 April 2020; Published: 1 May 2020

\begin{abstract}
The rigid polyurethane foam (PU) is a versatile material, used especially for construction and household applications. The current situation demands a facile, cost-efficient, and greener approach for developing the polyurethanes from bio-derived materials. In this study, we present a novel bio-polyol synthesized using carvone, an extract from caraway, spearmint, or dill seeds via facile thiol-ene reaction. Our one-step reaction uses a UV irradiation to allow the room temperature conversion of the carvone to a high purity bio-polyol, as confirmed from the standard analytical characterizations. The hydroxyl number of $365 \mathrm{mg} \mathrm{KOH} / \mathrm{g}$ close to its theoretical limit confirms the high conversion yield of the polyol for rigid PU synthesis. To overcome the flammability issues in PU, expandable graphite (EG) powder was used as an additive flame-retardant during the synthesis step. The resulting foams with EG maintained the uniform closed cell structure ( $>95 \%)$ with a high compression strength of $175 \mathrm{kPa}$. The addition of EG in PU results in the formation of a protective char layer during the flammability test and reduces the weight loss from $40.70 \%$ to $3.55 \%$ and burning time from 87 to $11 \mathrm{~s}$. Our results confirm that the carvone-based polyol can be a novel alternative to the petroleum polyols for an industrial-scale application.
\end{abstract}

Keywords: flammability; flame-retardant polyurethane foams; bio-polyol; expandable graphite

\section{Introduction}

Polyurethane (PU) foams are largely produced in the industry due to their versatile applications in construction, automobiles, footwears, and coatings [1,2]. Polyurethane foams can be synthesized by the reaction between an oligomeric polyol and a di- or poly-isocyanate in the presence of blowing agent $[3,4]$. Increasing global concerns regarding petroleum resources have raised the interest for sustainable synthesis of PU foams using bio-derived alternates. Our group has presented several alternative routes for synthesizing bio-derived PU foams to promote sustainability and reduce the carbon footprints [2,5-9]. Unsaturated double bonds available in vegetable oils from soybean, orange, castor, sunflower, and cardanol can be readily converted into polyols by reacting with a thiol-containing polyfunctional compound. Such a compound can introduce functional groups, such as the hydroxyl group via thiol-ene reaction resulting in polyol with reactive hydroxyl groups [10,11]. Similarly, carvone is one of the widely available bio-oils extracted from caraway (Carum carvi), spearmint (Mentha spicata), and dill, and can be used as a raw material for the synthesis of polyol [12]. Use of carvone for polyol 
synthesis has not been previously explored. Hence, it would be advantageous to study the properties of carvone-based polyol for the synthesis of PU foams.

All the PU foams obtained either via petrochemicals or renewable resources are made up of hydrocarbon compounds and possess a highly porous structure $[9,13]$. A small fire accident to such a structure can, therefore, result in a major fire. Especially when the rigid PU foams are used as thermal insulators in buildings, such accidents can cause serious casualties and property damage [13]. For this reason, several efforts have been made to obtain flame-retardant (FR) PU foams using a blended FR compound [2,9]. They can be of several types such as halogenated or non-halogenated, additive or reactive, and solid phase or gas phase FR compounds [14]. Non-halogenated additive flame-retardants are widely used since they can be added directly in predetermined quantity to impart flame-retardant properties in foams. A few examples of additive flame-retardants are expandable graphite (EG), melamine, dimethyl phosphate, ammonium phosphate, and aluminum trihydroxide [15-20]. Specifically, EG is a low-cost non-halogenated additive flame-retardant and is widely studied in the literature for various applications [21-23]. Its flame retardancy occurs due to the formation of a protective char layer on the surface, inhibiting fire growth. It is also used as a filler within the foams to reduce the overall cost of the foams [18,24]. However, extensive quantities can result in a systematic decrease in mechanical properties of the foams. Hence, the convention is to obtain high flame retardancy with a low possible concentration of flame-retardant without deteriorating the properties of PU foam.

In this study, we have synthesized a novel carvone-based polyol using a facile thiol-ene reaction. The polyol was characterized by Fourier transformed infrared (FT-IR), gel permeation chromatography (GPC), hydroxyl number, and viscosity. The PU foams characterizations made were apparent density, closed-cell content, compressive strength, scanning electron microscopy, and flammability test.

\section{Experimental}

\subsection{Materials}

Carvone, expandable graphite (EG), and photoinitiator, 2-hydroxy-2-methyl propiophenone, were obtained from Sigma-Aldrich, St. Louis, MO, USA. 2-mercaptoethanol (2-ME) was obtained from Acros Organic, Pittsburgh, PA, USA. Both catalysts NIAX A-1 and DABCO T-12 were obtained at Air Products, Allentown, PA, USA. Tegostab B-8404, used as a surfactant, was acquired from Evonik, Parsippany, NJ, USA. Methylene diisocyanate (MDI) and Jeffol 522, which is a commercial polyol, were kindly donated from Huntsman, the Woodlands, TX, USA. DI water was used as a blowing agent obtained from the local Walmart (Pittsburg, KS, USA).

\subsection{Synthesis of Carvone-Based Polyol}

For the synthesis of carvone-based polyol, one mol of carvone was reacted with $2 \mathrm{~mol}$ of 2-mercaptoethanol in the presence of 2-hydroxy-2-methyl propiophenone as a photoinitiator. The reaction was exposed to UV light $(365 \mathrm{~nm})$ under continuous stirring for $8 \mathrm{~h}$. Figure 1 shows the thiol-ene reaction for the synthesis of polyol.

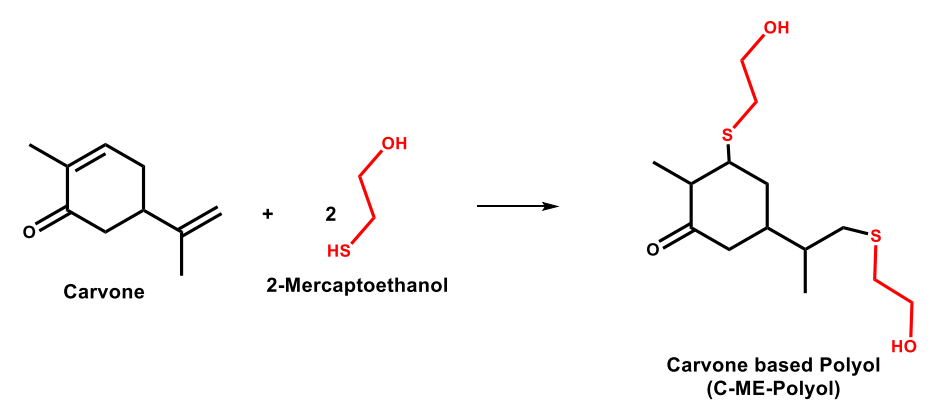

Figure 1. The chemical reaction for the synthesis of carvone-based polyol. 


\subsection{Polyol Characterizations}

The characterizations of synthesized carvone-based polyol were based on standards from ISO (International Organization for Standardization) and ASTM (American Society for Testing and Materials). By using the Hanus method, the iodine number for carvone was determined. The hydroxyl number of the polyol was obtained according to the ASTM E1899-16 Method by reacting the polyol with $p$-toluenesulfonyl isocyanate (TSI), followed by potentiometric titration (888 Titrando, Tiamo Software system by Metrohm, AG, Switzerland). The viscosity of carvone and the polyol was measured using a TA Instruments rheometer from New Castle, Delaware, at room temperature by increasing the shear stress from 0.1 to $100 \mathrm{~Pa}$. A cone plate with a $2^{\circ}$ angle and $12.5 \mathrm{~mm}$ radius was used. The FT-IR spectra were obtained using a PerkinElmer Spectrum two from Waltham, Maryland. Gel Permeation Chromatography (GPC) was performed into the polyol and starting materials using a Waters system from Milford, Massachusetts. The system consists of a column with the dimensions of $300 \times 7.8 \mathrm{~mm}$ with different pores from 50 and 102 to $104 \AA$. The standard eluent used was tetrahydrofuran, injecting $20 \mu \mathrm{L}$ for $50 \mathrm{~min}$ per sample at $30^{\circ} \mathrm{C}$.

\subsection{Synthesis of Flame-Retardant Rigid Polyurethane}

FR-PU foams were synthesized by using different concentrations of EG, shown in Table 1. Firstly, the polyol and EG were manually mixed in a $500 \mathrm{~mL}$ plastic cup and then vigorously stirred (3000 rpm) for a few minutes to form a homogenous mixture. All the components but MDI were added and stirred for $30 \mathrm{~s}$. Next, $33.39 \mathrm{~g}$ of MDI was added and vigorously stirred to obtain the PU foam. The samples were designated as EG 0, EG 0.5, EG 1.5, EG 3, EG 5, EG 8, and EG 10. The wt.\% of the biocomponent (biopolyol) in EG 0, EG 0.5, EG 1.5, EG 3, EG 5, EG 8, and EG 10 was 18.3, 18.1, 17.8, 17.3, 16.7, 15.9, and 15.4, respectively. A foam (Jeffol) containing only Jeffol 522 was also prepared for comparison.

Table 1. The formulation in grams of foam's components.

\begin{tabular}{ccccccccc}
\hline Compound & Jeffol & EG 0 & EG 0.5 & EG 1.5 & EG 3 & EG 5 & EG 8 & EG 10 \\
\hline C-2-ME-Polyol & 0 & 10 & 10 & 10 & 10 & 10 & 10 & 10 \\
Jeffol 522 & 20 & 10 & 10 & 10 & 10 & 10 & 10 & 10 \\
A-1 & 0.14 & 0.14 & 0.14 & 0.14 & 0.14 & 0.14 & 0.14 & 0.14 \\
Water & 0.8 & 0.8 & 0.8 & 0.8 & 0.8 & 0.8 & 0.8 & 0.8 \\
T-12 & 0.04 & 0.04 & 0.04 & 0.04 & 0.04 & 0.04 & 0.04 & 0.04 \\
B8404 & 0.4 & 0.4 & 0.4 & 0.4 & 0.4 & 0.4 & 0.4 & 0.4 \\
MDI & 37.14 & 33.39 & 33.39 & 33.39 & 33.39 & 33.39 & 33.39 & 33.39 \\
EG & 0 & 0 & 0.5 & 1.5 & 3 & 5 & 8 & 10 \\
Wt.\% of EG in the foam & 0 & 0 & 0.91 & 2.67 & 5.19 & 8.37 & 12.75 & 15.44 \\
\hline
\end{tabular}

\subsection{Characterizations of Polyurethane Foams}

The foams were cut in a cylinder of $45 \times 30(\mathrm{~mm})$ of diameter and height, respectively. These cylinders were used to measure apparent density and closed-cell content. Gravimetric density was obtained according to ASTM 1622-14. A Humi Pyc Volumetric and relative humidity (RH) Analyzer instrument was used to acquire the closed-cell content. The compressive strength of the PU foams was obtained by cutting them into $50 \times 50 \times 25\left(\mathrm{~mm}^{3}\right)$ length, width, and height, respectively. The strain at $10 \%$ and yield at break were determined by using an Instron tensile instrument (Raleigh, NS, USA) operated by the Blue Hill system, adopting the ISO 844:2016. The compressive strength applied was at a strain rate of $3 \mathrm{~cm} / \mathrm{min}$, from the top of the sample. Thermogravimetric Analysis (TGA) was performed using a Q500 Discovery (New Castle, DE, USA) to analyze the foam's thermal decomposition. TGA was performed in nitrogen and air starting from 20 to $700^{\circ} \mathrm{C}$, at a $10^{\circ} \mathrm{C}$ increase per min. Fire retardancy was determined by adopting the ASTM D 4986-18 standard test, which consisted of applying a direct flame into the sample with dimensions of $150 \times 50 \times 12.5\left(\mathrm{~mm}^{3}\right)$ height, length, and thickness respectively, 
in a horizontal position for $10 \mathrm{~s}$. After that, the time taken for the sample to quench the fire by itself along with the weight loss percentage was recorded. Cubicles of $0.5 \mathrm{~cm}^{3}$ dimensions were cut and used to obtain images for the Scanning Electron Microscopy (SEM) (Phenom, Netherlands). A Magnetron Sputtering along with a monitor from Kurt J. Lesker Company (Jefferson Hills, PA, USA) was used to perform a gold sputtering on the surface of the samples to coat them with a thin conductive layer of gold $(\mathrm{Au})$. The system was flushed several times with Ar gas. A vacuum of $50 \mathrm{mBar}$ was applied, and the samples were put under gold plasma for $1 \mathrm{~min}$.

\section{Results and Discussion}

The GPC chromatogram for carvone, 2-ME, and C-2-ME-Polyol are ascribed in Figure 2. The reduced retention time for C-2-ME-Polyol (36 $\mathrm{min}$ ) as compared to carvone (42 $\mathrm{min})$ suggests an increase in the molecular weight of polyol. No extra peaks were observed in GPC curves for unreacted compounds, which confirms that the reaction was complete. The carvone structure consists of two double bonds that have a difference in reactivity due to steric hindrance within the structure. Hence, the peak at 38 min could be linked to the external double bond of carvone reacted with 2-ME because of less steric hindrance, while the peak at $36 \mathrm{~min}$ could correspond to the occurrence of reaction on both the double bonds, as reported by others $[25,26]$. Further, the reaction proceeding for polyol synthesis can also be correlated to an increase in viscosity of C-2-ME-Polyol (2.702 Pa.s) compared to that of carvone (0.006173 Pa.s.). The viscosity of a commercial polyol (Jeffol 522) was 26.59 Pa.s. Jeffol 522 is a sucrose-based polyol with a hydroxyl number of $520 \mathrm{mg} \mathrm{KOH} / \mathrm{g}$ and a hydroxyl functionality of 5. Although the viscosity value for polyol showed an obvious increase as compared to carvone, it was low in terms of materials processing and mixing, and therefore allowed for easy processing of PU foams [9]. The hydroxyl number for the synthesized polyol was $365 \mathrm{mg} \mathrm{KOH} / \mathrm{g}$, while the theoretical value was $367 \mathrm{mg} \mathrm{KOH} / \mathrm{g}$, which suggested a high conversion of essential oil into polyol structure. Since the observed hydroxyl number of the synthesized polyol matches well with the theoretical value calculated using a reaction of one mol of carvone with two moles of 2-mercaptoethanol, the possibilities of reacting with only one double bond could be minimum. It is likely to form oligomers of the polyol. Figure 3 shows the possible reaction of the formation of minor products. Similar behavior was reported in thiol-ene chemistry by other researchers also $[25,26]$.

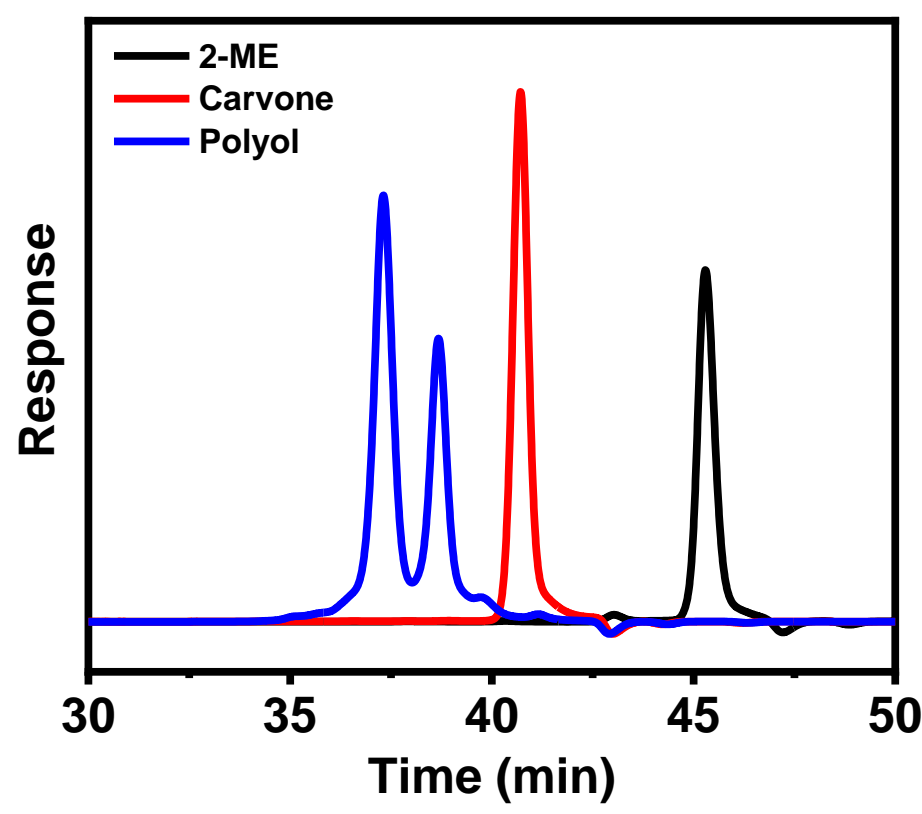

Figure 2. Gel Permeation Chromatogram for carvone, 2-mercaptoethanol (2-ME), and carvone-based polyol. 


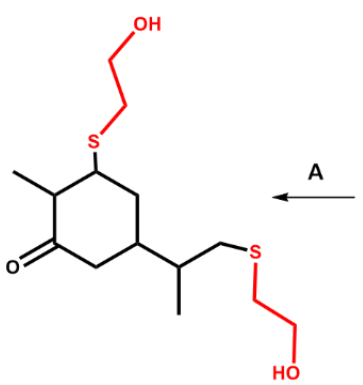

Carvone based Polyol (main product)

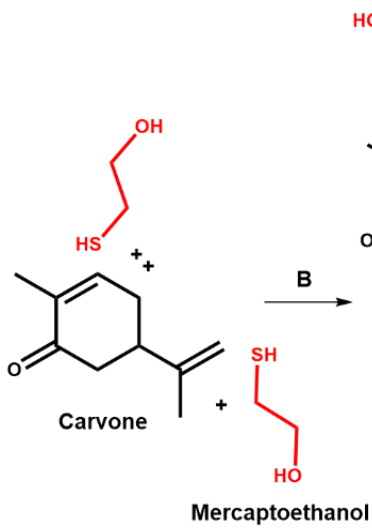

Mercaptoethanol

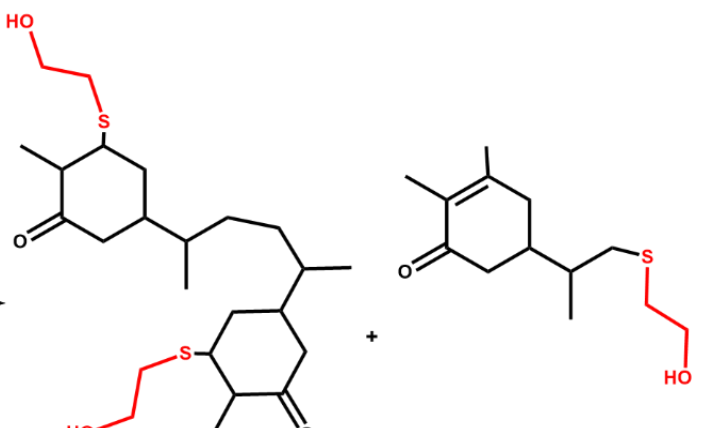

Minor products

Figure 3. The chemical reaction for the synthesis of carvone-based polyol (A) along with expected byproducts $(\mathbf{B})$.

The reaction proceedings for the thiol-ene reaction between carvone and 2-ME was analyzed using FT-IR spectra, shown in Figure 4. For carvone, a peak near $900 \mathrm{~cm}^{-1}$ correlates to an axial stretch for $\mathrm{C}=\mathrm{C}$ [27]. While, for 2-ME, a peak near $2568 \mathrm{~cm}^{-1}$ represents an axial stretch for S-H bond and $3500 \mathrm{~cm}^{-1}$ for $\mathrm{C}-\mathrm{O}-\mathrm{H}$ bond [28]. After the thiol-ene reaction, the $\mathrm{S}-\mathrm{H}$ peak near $2568 \mathrm{~cm}^{-1}$ and $\mathrm{C}=\mathrm{C}$ peak near $900 \mathrm{~cm}^{-1}$ disappeared by forming C-S bond near $600-700 \mathrm{~cm}^{-1}$, with a simultaneous appearance of C-O-H axial stretch at $3500 \mathrm{~cm}^{-1}$ for C-2-ME-Polyol $[5,25,29]$. Similar behavior was reported by Feng et al. for the synthesis of soybean oil and 2-ME-based polyol via thiol-ene reaction [28].

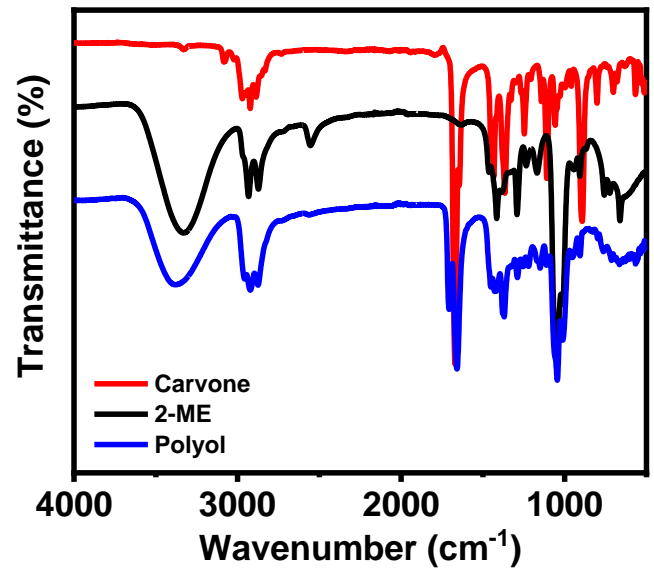

Figure 4. Fourier Transformed Infrared spectra for carvone, 2-mercaptoethanol, and carvone-based polyol.

The effect of EG concentration on an apparent density of PU foams is summarized in Figure 5. All the foams showed the apparent density in the range of $30-45 \mathrm{~kg} / \mathrm{m}^{3}$. The density of polyurethane foam prepared using commercial polyol (Jeffol 522) was $43 \mathrm{~kg} / \mathrm{m}^{3}$. As the amount of the EG exceeded $8.37 \mathrm{wt} . \%$ in the polyurethane foams, the density values for PU foams increased. This could be due to the presence of acidic groups on EG's surface that milds the effect of catalyst and slows down the rise time of the foams [21,30]. This caused a slight increase in the apparent density of the foams. The addition of a higher amount of catalyst could increase the rise time and maintain the density of foams [5]. However, all the densities were following industrial standards and can be used for rigid foam applications [26]. Hence, no further modifications were made to the concentration of the catalyst. The rise time for the foams EG 0, EG 0.5, EG 1.5, EG 3.0, EG 5.0, EG 8.0, and EG 10.0 was about 14, 14, $12,12,11,9$, and $8 \mathrm{~s}$, respectively. The rise time of the foam prepared using Jeffol 522 was about $13 \mathrm{~s}$. The closed-cell content of the prepared foams was measured using the ASTM D2856 method. Figure 6 shows the closed-cell content of all the foams. The closed-cell content of all the foams was observed in 
the range of $90 \%-95 \%$. The closed-cell content of polyurethane foam prepared using Jeffol 522 was 93\%. The FT-IR analysis of the prepared polyurethane foams was also performed (Figure 7). The peak around $3308 \mathrm{~cm}^{-1}$ is associated with the amide $(-\mathrm{NH})$ group, while the peak around $1699 \mathrm{~cm}^{-1}$ is due to the carbonyl urethane group $(-\mathrm{C}=\mathrm{O})$. The peaks around 1598,1515 , and $1225 \mathrm{~cm}^{-1}$ are indicative of $-\mathrm{C}-\mathrm{N},-\mathrm{C}=\mathrm{C}$, and $-\mathrm{C}-\mathrm{O}-\mathrm{C}$, respectively.

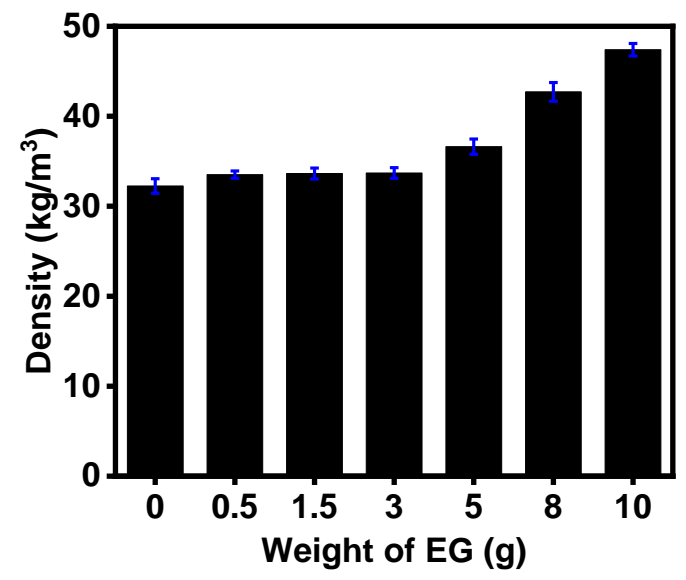

Figure 5. Density of polyurethane foams with carvone-based polyol with an increasing amount of EG.

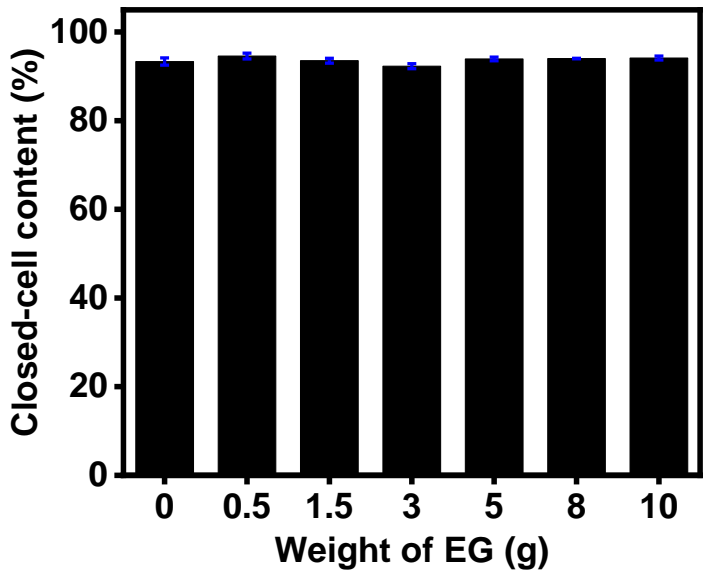

Figure 6. Closed-cell content of polyurethane foams with carvone-based polyol with an increasing amount of EG.

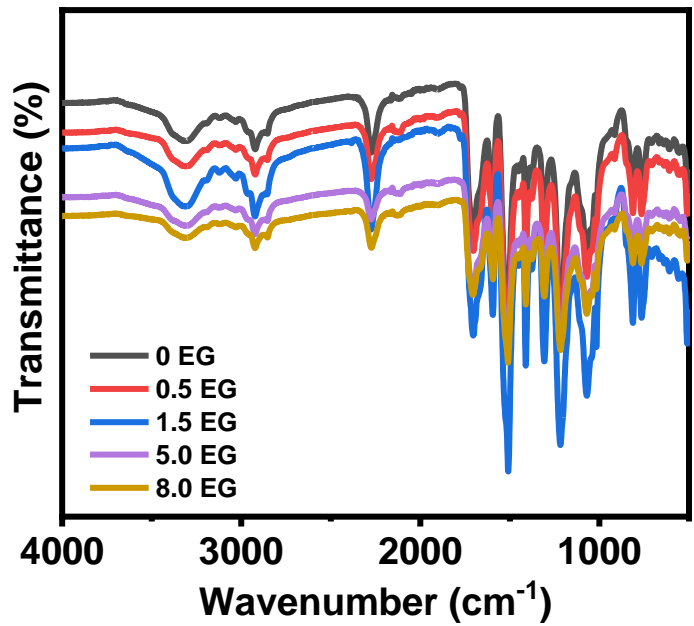

Figure 7. Fourier Transformed Infrared spectra for polyurethane foams. 
The SEM images for all the synthesized PU foams with uniform cellular structure can be summarized from Figure 8. Increasing the concentration of EG from 0 (C-EG-0) to 15.44 wt.\% (C-EG-10) decreases an average cell size from 160 to 120 micron. These results are in accordance with the density values. As the amount of EG exceeds $8.37 \mathrm{wt} . \%$ in the foam, the acid content within the reaction mixture of PU foam increases, which slows down the rise time of the foam and raises the apparent density of the foams. Unlike previous reports for PU foams containing EG, we observed a highly closed-cell structure $>95 \%$ for our EG containing PU foams, which could be due to compatibility of EG with carvone-based polyol structure [31,32]. A high and nearly constant value for closed-cell content with low variance in density can present rigid PU foams with good thermal insulation properties $[2,33]$.

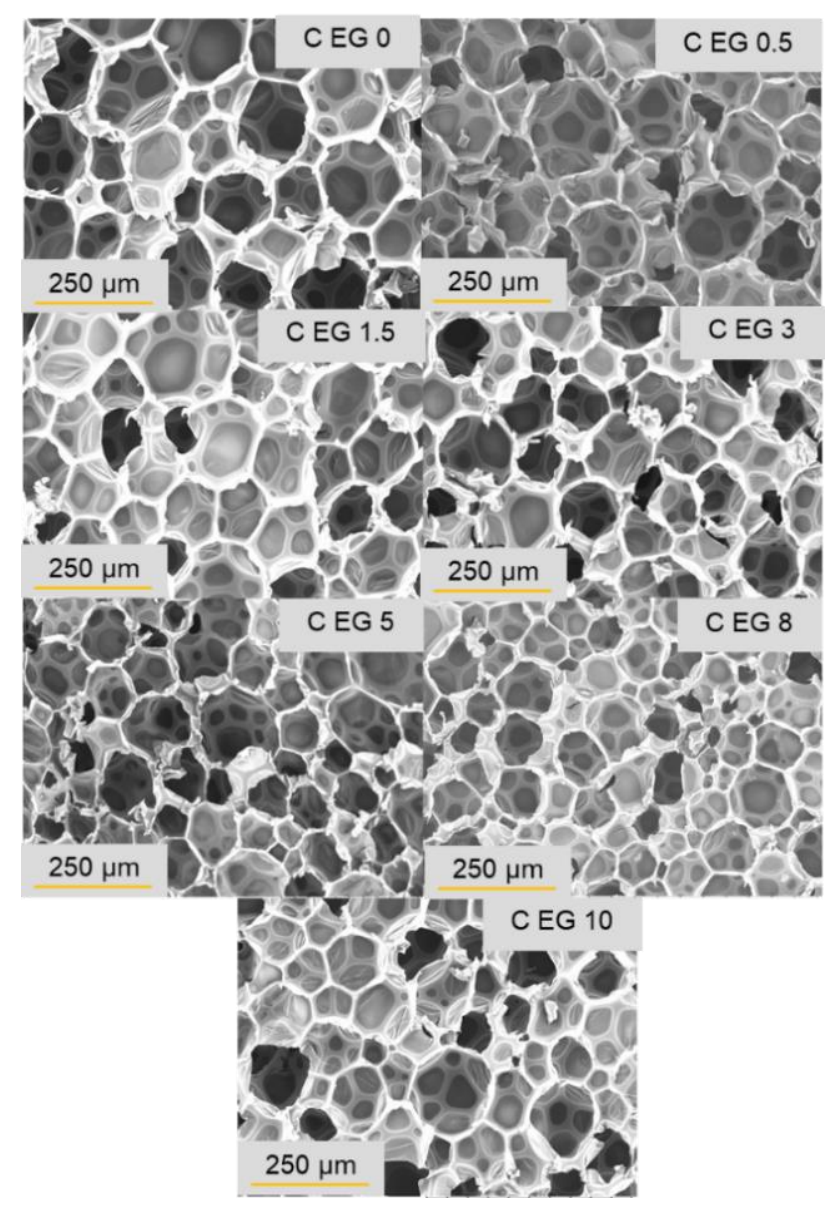

Figure 8. Scanning Electron Microscopy (SEM) of carvone-based PU with an increasing amount of EG.

A compression test was performed to analyze the effect of an increasing amount of EG on the mechanical properties of PU foams (Figure 9). EG is being reported as a cost-effective FR with the drawbacks of harder processing and a decrease of mechanical strength [24,34]. The ultimate compressive strength value was found to be $210 \mathrm{kPa}$ and $209 \mathrm{kPa}$ for neat PU foam prepared using synthesized biopolyol and Jeffol 522, respectively. As we increased the content of EG, the compression strength of PU foams slightly decreased. The $10 \mathrm{EG}-\mathrm{PU}$ foam showed a yield at the break of $175 \mathrm{kPa}$. Although EG acts as an effective FR when used in the form of flakes, its higher concentration in PU foams may cause defects into segments of the foam, hence it deteriorates some of its mechanical properties, causing the compressive strength to vary [21,24,35-38]. Even though there was a decrease in mechanical properties with increasing concentration of PU foams, all the EG-PU foams showed higher compression strength than foams originated from castor, cardanol, and corn oils that were 150, 130 , and $75 \mathrm{kPa}$, respectively [5,39]. 


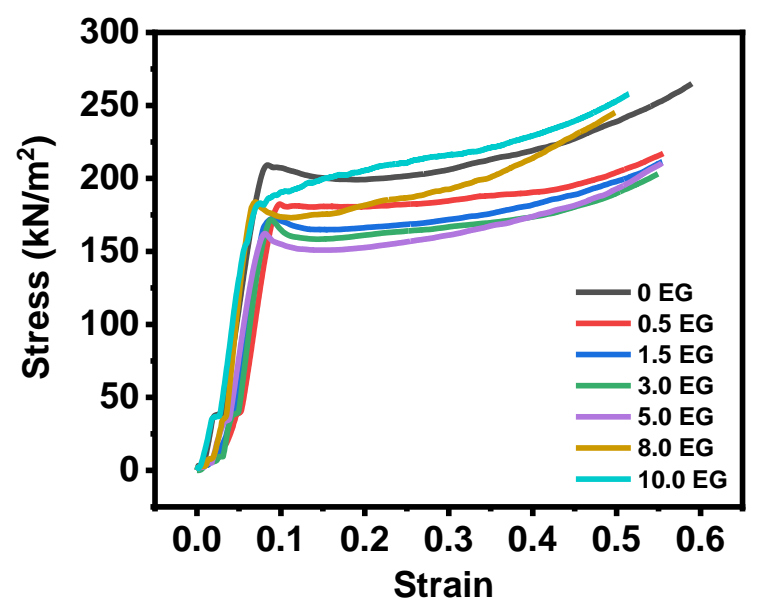

Figure 9. Compressive strength for carvone-based PU with an increasing amount of EG.

The flame-retardant properties of EG containing PU foams were analyzed using a horizontal burning test. In this study, the foams were held in the horizontal position and subjected to a fire for $10 \mathrm{~s}$. The flame time and weight loss after the self-extinction of fire were recorded (Figures 10 and 11). The neat PU showed the longest flame time of $98 \mathrm{~s}$ and the highest weight loss of $46 \%$. By adding $15.44 \mathrm{wt} . \%$ of EG (10 EG), the lowest flame time of $11 \mathrm{~s}$ and weight loss of $3.55 \%$ were achieved. A systematic reduction in the burnt area of samples with increasing EG content is summarized in Figure 12. However, with a further increase in EG concentration (>12.75 wt.\%), there were no major changes observed in flame-retardant properties of rigid PU foams. The foam prepared using Jeffol 522 displayed the burning time of $95 \mathrm{~s}$ with a weight loss of $44 \%$. The observed flame time was comparable to previously reported PU foams. For example, Ranaweera et al. prepared limonene-based FR-PU foams using DMMP as a flame-retardant [40]. The self-extinguish time for the best limonene-based FR-PU foam was reported to be $19 \mathrm{~s}$. Similarly, Ramanujam et al. reported a functionalized corn-based FR-PU foam using DMMP and presented remarkable fire-retardant properties by reducing the weight loss from $38 \mathrm{wt} . \%$ from the neat PU to $5.5 \mathrm{wt} . \%$ by addition of $1.94 \mathrm{wt} . \%$ of PU. Unlike EG, DMMP can release toxic fumes containing $\mathrm{PH}_{3}$ and it is almost five times more expensive than EG, which significantly increases the cost during the large-scale production. In contrast, EG also acts as a filler and can be used to reduce the overall cost of PU foams.

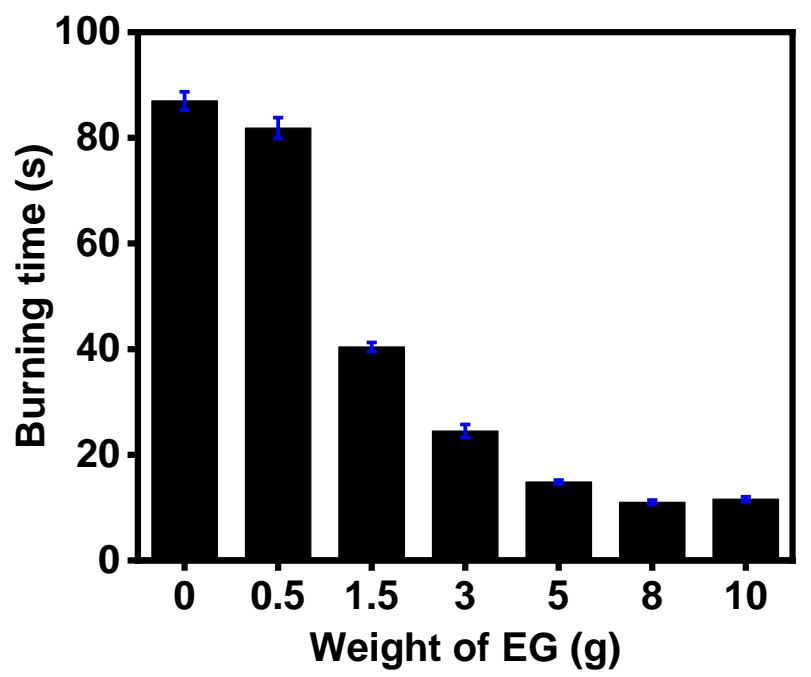

Figure 10. Burning time for the carvone-based PU foams with an increasing amount of EG. 


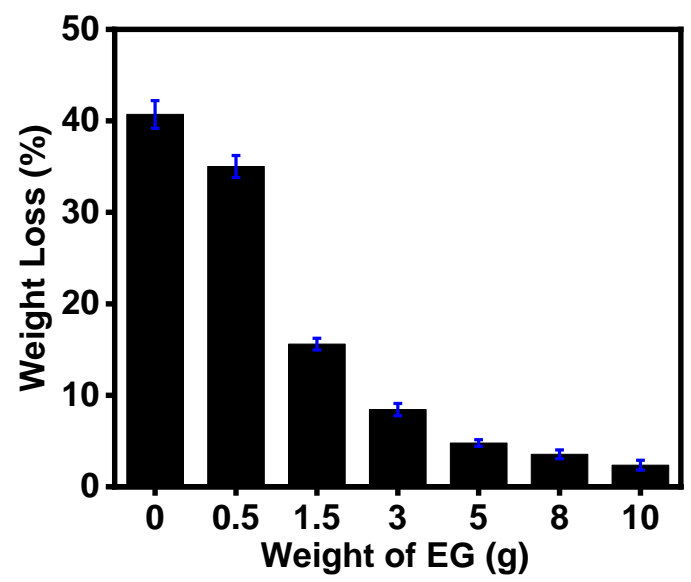

Figure 11. Weight loss for the PU foams with an increasing amount of EG after burning.
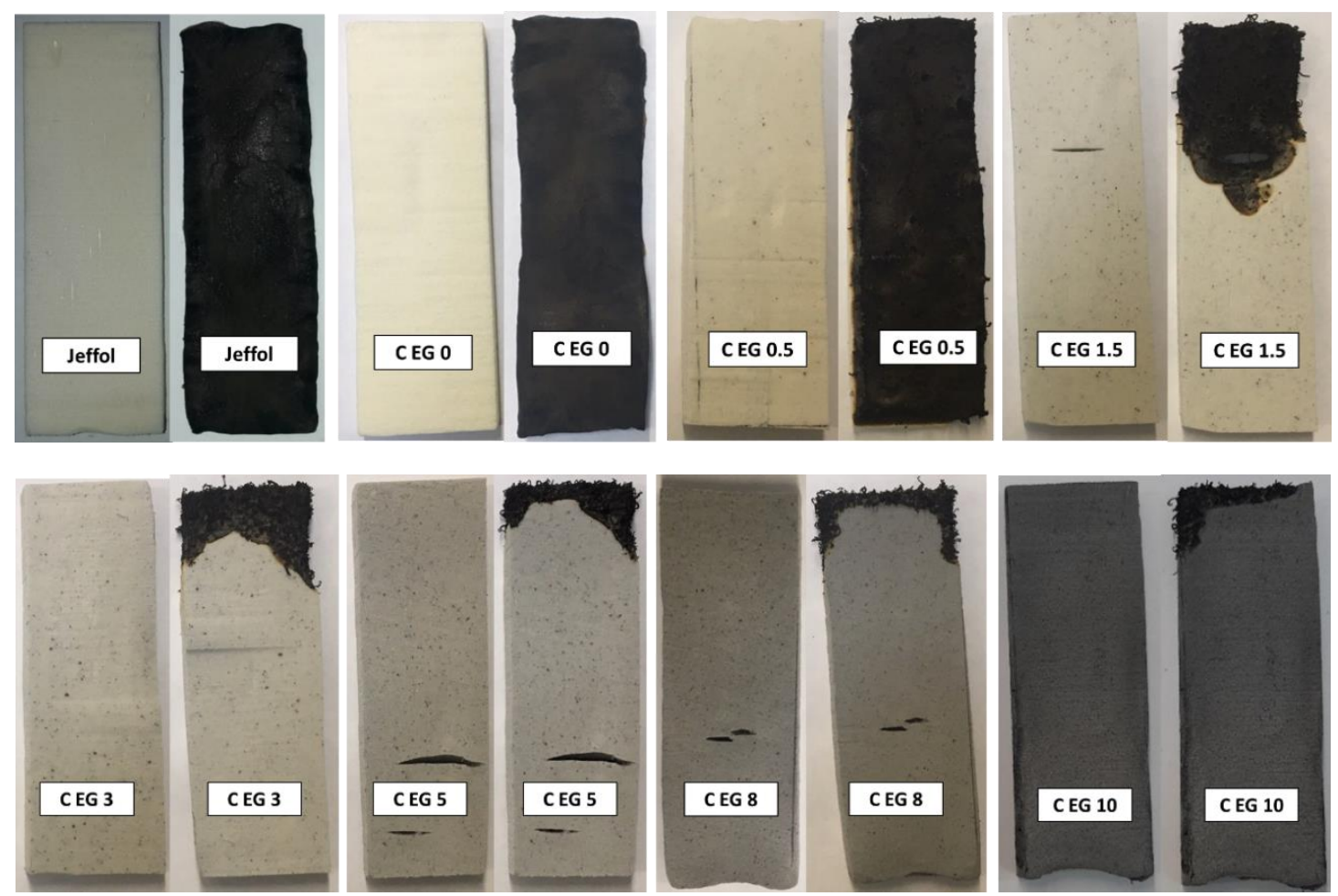

Figure 12. Photographs of the PU taken prior to and after the horizontal burning test.

The thermal analysis of FR-PU foams was performed using thermogravimetric analysis (TGA) and derivative thermogravimetric analysis (DTGA) in both a nitrogen and air atmosphere. Figure 13 shows the thermal properties of all the foams studied under a nitrogen atmosphere. The weight loss curve in TGA and DTGA shows two-step thermal decomposition behavior. At $250^{\circ} \mathrm{C}$, the hydrocarbon chains in PU foam start to decompose and EG activates and starts to expand, forming a protective char layer on the foam surface [21]. The first maximum decomposition occurs at $285^{\circ} \mathrm{C}$ (Figure 13b). It can be noted that with an increasing amount of EG, there was a systematic decrease in the weight loss of the foams. This means that protective char formation increases with EG concentration and stabilizes the surface of the foam. The EG pyrolysis comprises of $\mathrm{SO}_{2}, \mathrm{CO}_{2}$, and water that gets entrapped while escaping near the edges of the graphitic structure, leading to the irreversible expansion of the graphene structure [21]. The expansion then creates a graphitic char layer on the surface of the foam that prevents the heat transfer through the solid phase and stops the fire [21,24,35]. This type of phenomenon is observed by the expansion of foam surface during the burning test, which may sometimes form blisters 
of charred graphene. A second degradation peak near $550{ }^{\circ} \mathrm{C}$ corresponds to the disintegration of the PU structure along with char, resulting in weight loss for all the foams [35,41]. As compared to neat PU foams, EG containing foams showed relatively lower weight loss, suggesting increased char stability with EG concentration. The thermal behavior of the prepared foams studied under an air atmosphere is shown in Figure 14. The foams showed similar behavior under nitrogen and air atmosphere; however, the maximum decomposition temperature for the foams was observed to shift towards a lower temperature $\left(270^{\circ} \mathrm{C}\right)$ in air. In addition, at the higher temperature, the foams under air seem to reach maximum decomposition around $600{ }^{\circ} \mathrm{C}$. Some of the important thermal characteristics of the foams in nitrogen and air atmosphere are given in Table 2.
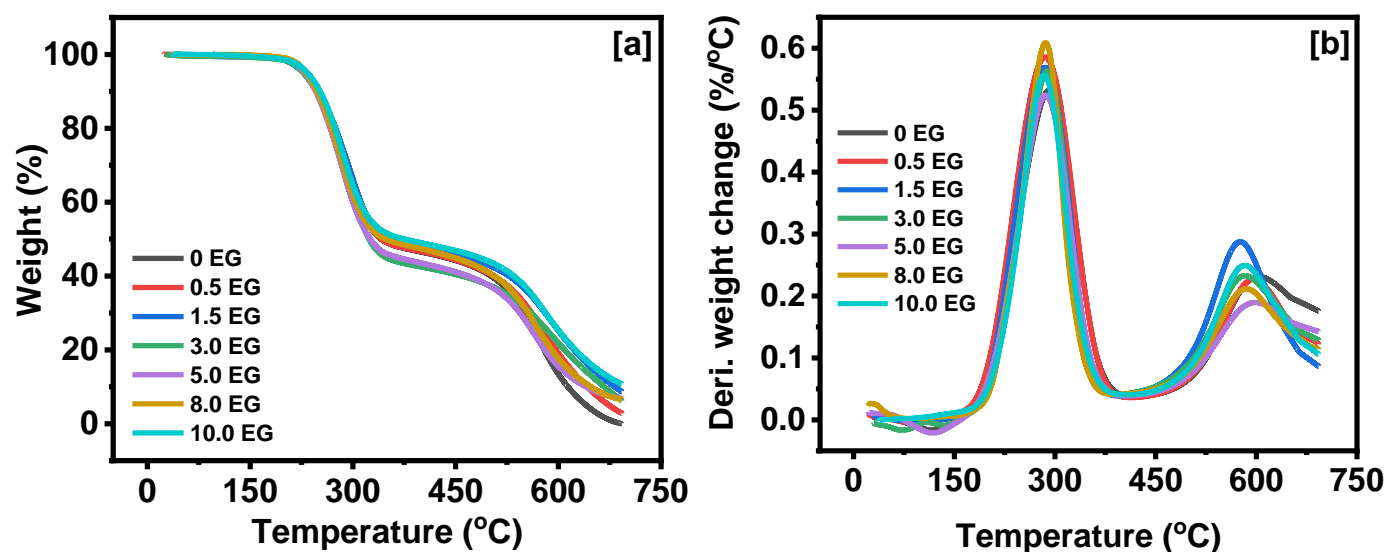

Figure 13. Thermogravimetric analysis (a) and derivative weight loss curves (b) of PU foams in a nitrogen environment.
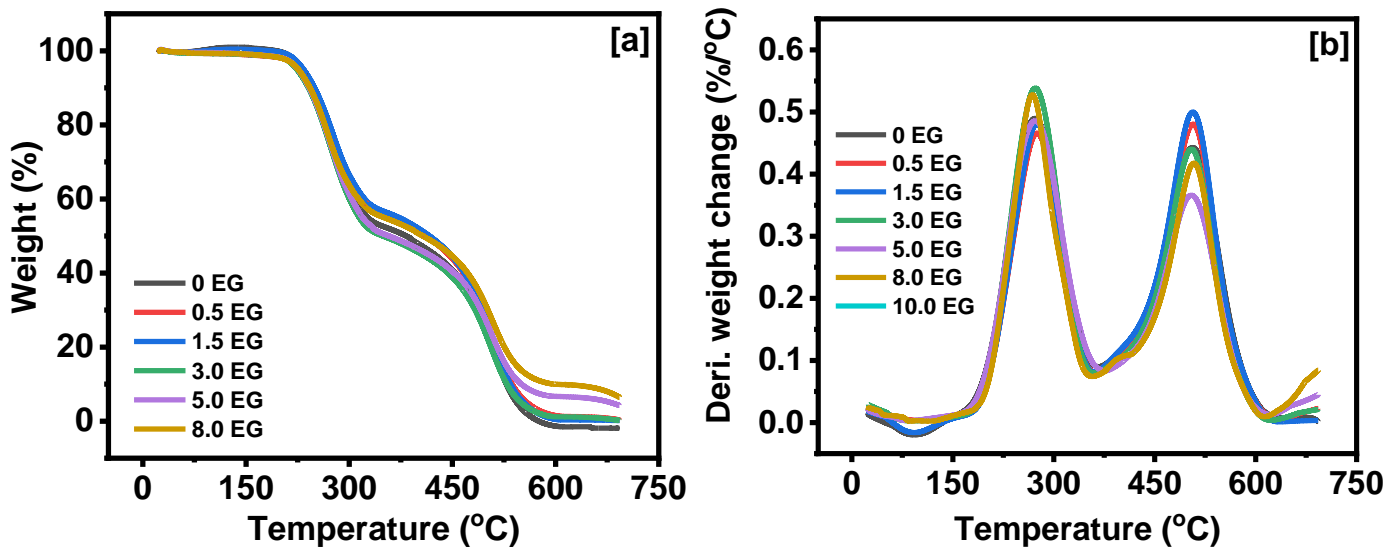

Figure 14. Thermogravimetric analysis (a) and derivative weight loss curves (b) of PU foams in an air environment.

Table 2. Thermal properties of the polyurethane foams.

\begin{tabular}{ccccccc}
\hline & $\mathbf{N}_{\mathbf{2}}$ & $\mathbf{N}_{\mathbf{2}}$ & $\mathbf{N}_{\mathbf{2}}$ & Air & Air & Air \\
\hline Foam & $\mathbf{T}_{\mathbf{d} \text { \% }}$ & $\mathbf{T}_{\mathbf{d} \mathbf{0} \%}$ & $\mathbf{T}_{\mathbf{d m a x}}$ & $\mathbf{T}_{\mathbf{d} 5 \%}$ & $\mathbf{T}_{\mathbf{d} \mathbf{0} \%}$ & $\mathbf{T}_{\mathbf{d m a x}}$ \\
\hline 0 EG & 231.2 & 250.0 & 700 & 231.6 & 246.3 & 700 \\
0.5 EG & 233.0 & 251.2 & 700 & 226.9 & 245.5 & 700 \\
1.5 EG & 228.0 & 249.7 & 700 & 233.5 & 249.7 & 700 \\
3.0 EG & 227.8 & 246.4 & 700 & 224.0 & 240.9 & 700 \\
5.0 EG & 229.6 & 245.8 & 700 & 225.7 & 242.2 & 700 \\
8.0 EG & 231.4 & 247.9 & 700 & 225.9 & 243.1 & 700 \\
\hline
\end{tabular}




\section{Conclusions}

The bio-based PU foams were successfully synthesized using a bio-oil named carvone and converted into a polyol using a facile and single-step thiol-ene reaction. The synthesized polyol was used as a sustainable alternative to petroleum-based polyol to make polyurethane foams. To enhance the flame retardancy in PU foams, we added different concentrations of EG during the synthesis step. All the synthesized PU foams showed an average apparent density of $45 \mathrm{~kg} / \mathrm{m}^{3}$ and a closed-cell content higher than $95 \%$. SEM analysis confirmed that the addition of EG had no adverse effect on the cellular structure of the PU foams. Although an increase in EG content showed a slight decrease in the ultimate compressive strength of the PU foams, the obtained values were comparably higher than commercially available PU foams. Moreover, the horizontal burning test showed an effective drop-in self-quenching fire from 98 to $11 \mathrm{~s}$, and respective weight loss from $40.7 \%$ to $2.36 \%$, as the EG concentration increased from 0 to $15.44 \mathrm{wt} . \%$. Both carvone and EG are widely available at relatively low-cost, therefore making them favorable to synthesize low-cost FR-PU foams for an industrial application.

Author Contributions: R.K.G. conceived the project and designed the experiments. F.M.d.S. performed the experiments. J.C. helped in flammability testing. S.B. took the SEM images and revised the manuscript. F.M.d.S. wrote the original draft. All authors reviewed the manuscript and provided their inputs. All authors have read and agreed to the published version of the manuscript.

Funding: This research received no external funding.

Acknowledgments: Ram K. Gupta expresses his sincere acknowledgment of the Polymer Chemistry Program and Kansas Polymer Research Center, Pittsburg State University, for providing financial and research support.

Conflicts of Interest: The authors declare no conflict of interest.

\section{References}

1. Zhang, C.; Yan, M.; Cochran, E.W.; Kessler, M.R. Biorenewable Polymers Based on Acrylated Epoxidized Soybean Oil and Methacrylated Vanillin. Mater. Today 2015, 5, 18-22. [CrossRef]

2. Zhang, C.; Bhoyate, S.; Ionescu, M.; Kahol, P.K.; Gupta, R.K. Highly Flame Retardant and Bio-Based Rigid Polyurethane Foams Derived from Orange Peel Oil. Polym. Eng. Sci. 2018, 58, 2078-2087. [CrossRef]

3. Zhang, C.; Madbouly, S.A.; Kessler, M.R. Biobased Polyurethanes Prepared from Different Vegetable Oils. ACS Appl. Mater. Interfaces 2015, 7, 1226-1233. [CrossRef] [PubMed]

4. Javni, I.; Zhang, W.; Petrović, Z.S. Effect of Different Isocyanates on the Properties of Soy-Based Polyurethanes. J. Appl. Polym. Sci. 2003, 88, 2912-2916. [CrossRef]

5. Ramanujam, S.; Zequine, C.; Bhoyate, S.; Neria, B.; Kahol, P.; Gupta, R. Novel Biobased Polyol Using Corn Oil for Highly Flame-Retardant Polyurethane Foams. C-J. Carbon Res. 2019, 5, 13. [CrossRef]

6. Bhoyate, S.; Ionescu, M.; Kahol, P.K.; Gupta, R.K. Castor-Oil Derived Nonhalogenated Reactive Flame-Retardant-Based Polyurethane Foams with Significant Reduced Heat Release Rate. J. Appl. Polym. Sci. 2018, 47276. [CrossRef]

7. Bhoyate, S.; Ionescu, M.; Kahol, P.K.; Gupta, R.K. Sustainable Flame-Retardant Polyurethanes Using Renewable Resources. Ind. Crops Prod. 2018, 123, 480. [CrossRef]

8. Bhoyate, S.; Ionescu, M.; Radojcic, D.; Kahol, P.K.; Chen, J.; Mishra, S.R.; Gupta, R.K. Highly Flame-Retardant Bio-Based Polyurethanes Using Novel Reactive Polyols. J. Appl. Polym. Sci. 2018, 135. [CrossRef]

9. Bhoyate, S.; Ionescu, M.; Kahol, P.K.; Chen, J.; Mishra, S.R.; Gupta, R.K. Highly Flame-Retardant Polyurethane Foam Based on Reactive Phosphorus Polyol and Limonene-Based Polyol. J. Appl. Polym. Sci. 2018, 135, 16-19. [CrossRef]

10. Ding, H.; Huang, K.; Li, S.; Xu, L.; Xia, J.; Li, M. Synthesis of a Novel Phosphorus and Nitrogen-Containing Bio-Based Polyol and Its Application in Flame Retardant Polyurethane Foam. J. Anal. Appl. Pyrolysis 2017, 128, 102-113. [CrossRef]

11. Montero de Espinosa, L.; Meier, M.A.R. Plant Oils: The Perfect Renewable Resource for Polymer Science?! Eur. Polym. J. 2011, 47, 837-852. [CrossRef]

12. De Carvalho, C.C.C.R.; da Fonseca, M.M.R. Carvone: Why and How Should One Bother to Produce This Terpene. Food Chem. 2006, 95, 413-422. [CrossRef] 
13. Babrauskas, V.; Lucas, D.; Eisenberg, D.; Singla, V.; Dedeo, M.; Blum, A. Flame Retardants in Building Insulation: A Case for Re-Evaluating Building Codes. Build. Res. Inf. 2012, 40, 738-755. [CrossRef]

14. Levchik, S.V.; Weil, E.D. A Review of Recent Progress in Phosphorus-Based Flame Retardants. J. Fire Sci. 2006, 24, 345-364. [CrossRef]

15. Wang, L.; He, X.; Wilkie, C.A. The Utility of Nanocomposites in Fire Retardancy. Materials (Basel) 2010, 3, 4580-4606. [CrossRef] [PubMed]

16. Liu, F.; Ding, X.; Su, Y. Properties of Rigid Polyurethane Foams Produced by the Addition of Phosphorus Compounds. Am. J. Mater. Res. 2014, 1, 14-19.

17. Chen, Y.; Jia, Z.; Luo, Y.; Jia, D.; Li, B. Environmentally Friendly Flame-Retardant and Its Application in Rigid Polyurethane Foam. Int. J. Polym. Sci. 2014, 2014. [CrossRef]

18. Xing, W.; Yuan, H.; Zhang, P.; Yang, H.; Song, L.; Hu, Y. Functionalized Lignin for Halogen-Free Flame Retardant Rigid Polyurethane Foam: Preparation, Thermal Stability, Fire Performance and Mechanical Properties. J. Polym. Res. 2013, 20, 234. [CrossRef]

19. Konig, A.; Malek, A.; Fehrenbacher, U.; Brunklaus, G.; Wilhelm, M.; Hirth, T. Silane-Functionalized Flame-Retardant Aluminum Trihydroxide in Flexible Polyurethane Foam. J. Cell. Plast. 2010, 46, 395. [CrossRef]

20. Wu, D.; Zhao, P.; Liu, Y. Flame Retardant Property of Novel Intumescent Flame Retardant Rigid Polyurethane Foams. Polym. Eng. Sci. 2013, 53, 2478-2485. [CrossRef]

21. Camino, G.; Duquesne, S.; Delobel, R.; Eling, B.; Lindsay, C.; Roels, T. Mechanism of Expandable Graphite Fire Retardant Action in Polyurethanes. ACS Symp. Ser. 2001, 797, 90-109. [CrossRef]

22. Bhoyate, S.; Mensah-Darkwa, K.; Kahol, P.K.; Gupta, R.K. Recent Development on Nanocomposites of Graphene for Supercapacitor Applications. Curr. Graphene Sci. 2017, 1, 26. [CrossRef]

23. Bhoyate, S.; Mensah-Darkwa, K.; Kahol, P.K.; Gupta, R.K. Advancement in Light Energy Harvesting by Using Tailored Graphene in DSSC and BHJ Solar Cells. Curr. Graphene Sci. 2019, 3, 1. [CrossRef]

24. Gupta, R.; Ionescu, M.; Wan, X.; Radojcic, D.; Bilic, N. New Polyols with Isocynauric Structure by Thiol-Ene "Click" Chemistry Reactions. J. Cell. Plast. 2017, 53, 639-662. [CrossRef]

25. Wilbon, P.A.; Chu, F.; Tang, C. Progress in Renewable Polymers from Natural Terpenes, Terpenoids, and Rosin. Macromol. Rapid Commun. 2013, 34, 8-37. [CrossRef] [PubMed]

26. Elbers, N.; Ranaweera, C.K.; Ionescu, M.; Wan, X.; Kahol, P.K.; Gupta, R.K. Synthesis of Novel Biobased Polyol via Thiol-Ene Chemistry for Rigid Polyurethane Foams. J. Renew. Mater. 2017, 5, 74-83. [CrossRef]

27. Desroches, M.; Caillol, S.; Lapinte, V.; Auvergne, R.M.; Boutevin, B. Synthesis of Biobased Polyols by Thiol-Ene Coupling from Vegetable Oils. Macromolecules 2011, 44, 2489. [CrossRef]

28. Feng, Y.; Liang, H.; Yang, Z.; Yuan, T.; Luo, Y.; Li, P.; Yang, Z.; Zhang, C. A Solvent-Free and Scalable Method To Prepare Soybean-Oil-Based Polyols by Thiol-Ene Photo-Click Reaction and Biobased Polyurethanes Therefrom. ACS Sustain. Chem. Eng. 2017, 5, 7365-7373. [CrossRef]

29. Kolb, H.C.; Finn, M.G.; Sharpless, K.B. Click Chemistry: Diverse Chemical Function from a Few Good Reactions. Angew. Chem. Int. Ed. 2001, 40, 2004-2021. [CrossRef]

30. Liu, Y.; He, J.; Yang, R. Effects of Dimethyl Methylphosphonate, Aluminum Hydroxide, Ammonium Polyphosphate, and Expandable Graphite on the Flame Retardancy and Thermal Properties of Polyisocyanurate-Polyurethane Foams. Ind. Eng. Chem. Res. 2015, 54, 5876-5884. [CrossRef]

31. Wang, W.J.; He, K.; Dong, Q.X.; Fan, Y.; Zhu, N.; Xia, Y.B.; Li, H.F.; Wang, J.; Yuan, Z.; Wang, E.P.; et al. Influence of Aluminum Hydroxide and Expandable Graphite on the Flammability of Polyisocyanurate-Polyurethane Foams. Appl. Mech. Mater. 2013, 368, 741. [CrossRef]

32. Gharehbaghi, A.; Bashirzadeh, R.; Ahmadi, Z. Polyurethane Flexible Foam Fire Resisting by Melamine and Expandable Graphite: Industrial Approach. J. Cell. Plast. 2011, 47, 549. [CrossRef]

33. Hejna, A.; Kirpluks, M.; Kosmela, P.; Cabulis, U.; Haponiuk, J.; Piszczyk, Ł. The Influence of Crude Glycerol and Castor Oil-Based Polyol on the Structure and Performance of Rigid Polyurethane-Polyisocyanurate Foams. Ind. Crops Prod. 2017, 95, 113-125. [CrossRef]

34. Hu, X.-M.; Wang, D.-M. Enhanced Fire Behavior of Rigid Polyurethane Foam by Intumescent Flame Retardants. J. Appl. Polym. Sci. 2013, 129, 238-246. [CrossRef]

35. Wang, Y.; Wang, F.; Dong, Q.; Xie, M.; Liu, P.; Ding, Y.; Zhang, S.; Yang, M.; Zheng, G. Core-Shell Expandable Graphite @ Aluminum Hydroxide as a Flame-Retardant for Rigid Polyurethane Foams. Polym. Degrad. Stab. 2017, 146, 267-276. [CrossRef] 
36. Shi, L.; Li, Z.-M.; Xie, B.-H.; Wang, J.-H.; Tian, C.-R.; Yang, M.-B. Flame Retardancy of Different-Sized Expandable Graphite Particles for High-Density Rigid Polyurethane Foams. Polym. Int. 2006, 55, 862-871. [CrossRef]

37. Tan, S.Q.; Abraham, T.; Ference, D.; Macosko, C.W. Rigid Polyurethane Foams from a Soybean Oil-Based Polyol. Polymer (Guildf) 2011, 52, 2840. [CrossRef]

38. Zhang, L.; Zhang, M.; Hu, L.; Zhou, Y. Synthesis of Rigid Polyurethane Foams with Castor Oil-Based Flame Retardant Polyols. Ind. Crops Prod. 2014, 52, 380-388. [CrossRef]

39. Liu, C.; Wang, C.; Hu, Y.; Zhang, F.; Shang, Q.; Lei, W.; Zhou, Y.; Cai, Z. Castor Oil-Based Polyfunctional Acrylate Monomers: Synthesis and Utilization in UV-Curable Materials. Prog. Org. Coat. 2018, 121, 236-246. [CrossRef]

40. Ranaweera, C.K.; Ionescu, M.; Bilic, N.; Wan, X.; Kahol, P.K.; Gupta, R.K. Biobased Polyols Using Thiol-Ene Chemistry for Rigid Polyurethane Foams with Enhanced Flame-Retardant Properties. J. Renew. Mater. 2017, 5, 1. [CrossRef]

41. Ye, L.; Meng, X.-Y.; Liu, X.-M.; Tang, J.-H.; Li, Z.-M. Flame-Retardant and Mechanical Properties of High-Density Rigid Polyurethane Foams Filled with Decabrominated Dipheny Ethane and Expandable Graphite. J. Appl. Polym. Sci. 2009, 111, 2372-2380. [CrossRef]

(C) 2020 by the authors. Licensee MDPI, Basel, Switzerland. This article is an open access article distributed under the terms and conditions of the Creative Commons Attribution (CC BY) license (http://creativecommons.org/licenses/by/4.0/). 